RE U I S T A D E E S T U D I O S I N T E R NA C I O NALA

\title{
Integración latinoamericana en el siglo XXI
}

Sergio Bitar

\section{Documento}

Exposición realizada en el Seminario Internacional "Integración latinoamericana y caribeña: empresa necesaria y posible", cuando por entonces era senador, en Caracas, Venezuela, entre el 25 y 26 de julio de 2001.

Hemos recorrido un largo trayecto y acumulado vasta experiencia. Mas los frutos han sido escasos. Al comenzar el siglo XXI, enfrentamos un cuadro internacional de globalización acelerada que hace más indispensable que nunca la integración.

La realidad mundial ha inducido a los gobiemos latinoamericanos a realizar una acción más enérgica. En menos de dos años, 2000 y 2001, hemos visto la adopción de acuerdos que van configurando un nuevo marco estratégico.

Este marco estratégico se constituye con la Carta Democrática (que define compromisos de fortalecimiento de instituciones democráticas, participación, respeto a los derechos humanos), la Carta Social (acuerdo de reducir la pobreza, la desigualdad), Zona de Paz (fronteras seguras, resolución pacífica de conflictos, reducción del gasto militar) y programa de Infraestructura e Informática (espacio económico latinoamericano conectado) ${ }^{1}$.

1 En particular menciono:

1. El 17 de julio, en La Paz (Diálogo Mercosur-CAN + Chile). Se acuerda establecer un mecanismo de diálogo y concertación política y se acuerda apro- 
Integración

latinoamericana

en el siglo XXI
Ahora corresponde constituir instancias de decisión para materializar estos principios, y diseñar y ejecutar proyectos concretos. ¿Por qué los frutos han sido escasos?

El proceso de integración latinoamericano ha mostrado dos insuficiencias.

Primero, una insuficiencia política. El pensamiento económico que inspiró la acción de los gobiemos se focalizó en un solo propósito: equilibrios macroeconómicos y apertura comercial. La integración asumió un carácter "comercialista". La lógica desarrollista se esfumó. La deuda y la inflación agobiaron a los países. Descuidamos la mirada estratégica, los factores del crecimiento y la equidad. La integración, como proceso político, tuvo una importancia menor.

Segundo, una insuficiencia operativa: buenos discursos y pocos programas; mucha declaración de intenciones, poco seguimiento de los resultados.

Al comenzar el siglo XXI se abre una nueva oportunidad, pues el entendimiento latinoamericano se torna indispensable para cada uno de nuestros países.

La integración es un proceso político

El nuevo impulso para la coordinación de los países latinoamericanos debe provenir del ámbito político. No basta con dejar funcionando acuerdos comerciales. Por cierto, un éxito comercial anima al entendimiento político, pero es imprescindible una mirada larga que promueva desde múltiples ángulos la cooperación latinoamericana y ésa es una resolución política.

bar una Carta Democrática en Lima, junto con la OEA. Se señala el respaldo a un Proyecto de Creación de Zonas de Paz.

2. E1 30 de junio en Buenos Aires (Mercosur + Chile + Bolivia). Se acuerda un Compromiso Social, y se señalan áreas de coordinación para establecer compromisos conjuntos en educación, nutrición, vejez, discapacidad, migración, etc.

3. El 23 y 24 de junio en Valencia, Venezuela (CAN). Se acuerda propiciar una convergencia con Mercosur y CAN, coordinarse para negociar con ALCA y $\mathrm{OMC}$ e impulsar proyectos comunes de infraestructura.

4. E1 22 de junio, en Asunción (jefes de Estado Mercosur + Chile). Se acuerda realizar una negociación conjunta con ALCA y OMC.

5. El 1 de septiembre de 2000, en Montevideo y Santa Cruz. Se afina una acción para Integración de Infraestructura Regional de América del Sur y ejes de interconexión. 
La globalización será absorbente, devoradora, desdibujante, si no es enfrentada con una articulación latinoamericana fundada en su propia identidad política, económica y cultural.

Como la globalización es inescapable, la unidad latinoamericana es una exigencia para lograr una mejor inserción, con más competitividad y equidad.

Por más pragmático que sea un enfoque, atendiendo sólo a los intereses económicos, los pueblos y sus gobiernos se mueven por sentimientos de más profundidad. Lo que inspira una acción concertada es un proyecto nuevo de sociedad, sustentado en una historia común, la empatía linguíística y religiosa, la similitud de problemas y soluciones y, en definitiva, una esperanza que sólo podemos construir unidos.

La principal falencia para sostener una iniciativa pujante es la ausencia de un sentido común estratégico compartido, de un proyecto conjunto, comprendido por nuestros pueblos. La conveniencia de una agrupación latina para participar con éxito en la globalización debe ser avizorada mejor por nosotros mismos, más allá de la coyuntura.

La reciente reflexión sobre la expansión de la Unión Europea es riquísima y sugerente para la gestación de un pensamiento latinoamericano.

Si bien esa reflexión apunta a las nuevas formas institucionales (federación de Estados o de naciones, parlamento y gobierno Europeos rediseñados), se inspira en consideraciones más esenciales. El Primer Ministro de Francia, Lionel Jospin, expresaba en mayo de 2001: "Europa es mucho más que un mercado. Es portadora de un modelo de sociedad".

Es ese proyecto de sociedad el que los latinoamericanos debemos gestar para hacer que la integración sea vista por la gente de nuestros países como un proyecto útil y no una mera declaración abstracta.

¿Tenemos un proyecto político común en América Latina? Algo se ha avanzado en el sur. Entre los progresos están el Mercosur, a pesar de sus entrabamientos; la convergencia Mercosur-CAN (Comunidad Andina de Naciones); la Carta Democrática y de Derechos Humanos, la Carta Social, la Zona de Paz, el Programa de Infraestructura.

Sin embargo, no existe entre nosotros una visión compartida de América Latina para el futuro. Queremos una sociedad más 
Integración

latinoamericana

en el siglo XXI democrática, de paz, de igualdad de oportunidades, con más tecnología y educación, es cierto, pero debemos diseñar una estrategia y hacerla realidad con programas viables.

¿Cómo promover la integración en medio de la globalización? A mi juicio, son tres los pilares en que se debe apoyar una nueva plataforma integracionista: a)reforzamiento del espacio político común; b) convergencia de las políticas económicas; e) conectividad de la infraestructura y las telecomunicaciones.

\section{REFORZAMIENTO DEL ESPACIO POLÍTICO}

Subsiste un doble déficit institucional para alentar la integración: un déficit ejecutivo (ausencia de órganos de decisión regional) y un déficit de normativas comunes (debilidad del Parlamento Latinoamericano, entre otros).

La coordinación intergubernamental es insuficiente, hay escaso seguimiento y menos aún un ámbito de decisión regional (latinoamericano). Debemos instalar instancias y procedimientos para hacer el seguimiento de los acuerdos y adoptar medidas prácticas.

A su vez, el Parlamento Latinoamericano, creado en 1964, es un espacio perfectible. Primero, cabe considerar un sistema de elección directa de parlamentarios latinoamericanos en cada país y ampliar los ámbitos de resolución legislativa comunes. Hay áreas de conveniencia para todos: normas de protección y promoción de inversiones, sistema de resolución de conflictos, combate a la droga y lavado de dinero, normas que garanticen los derechos humanos (respaldo a la Comisión Interamericana y al Tribunal Penal Internacional), protección del medio ambiente, entre otros. Estos avances generarían más estabilidad y seguridad jurídica en nuestra región.

Existe además otro campo de acción política prioritario: coordinarnos para abordar un eventual Acuerdo de Libre Comercio de las Américas (ALCA) y una posición común para negociar en la Organización Mundial de Comercio (OMC). Tenemos un claro interés conjunto para limitar y regular prácticas antidumping de Estados Unidos, subsidios agrícolas, normas paraarancelarias, propiedad intelectual y solución de controversias. 
No progresaremos en la integración económica si no logramos más estabilidad en nuestras relaciones. La democracia crea más confianza política. Pero la inestabilidad de las políticas económicas alienta la desconfianza. Es esencial avanzar hacia la convergencia de las políticas económicas.

¿De qué vale una rebaja del $10 \%$ del arancel entre nuestros países si es seguida de una devaluación inesperada del $20 \%$ de uno de los socios?

La política cambiaria es una pieza fundamental. La opción de "dolarizar" que puedan adoptar algunos países es, a mi juicio, una tremenda barrera a la integración, difícil de franquear si cada país actúa de manera distinta. Este tema amerita estudios para precisar sus consecuencias económicas y sociales.

Las políticas fiscal y cambiaria deben enmarcarse y moverse progresivamente hacia ciertos rangos convenidos por los países. Debemos apuntar a un "Maastricht" Latinoamericano.

\section{Conectividad de América Latina}

E1 tercer pilar para un impulso integrador es la conectividad. Un proyecto de modernización regional requiere de un programa de infraestructura, energía y redes de informática. Si tuviéramos que priorizar, creo que ésta debe ser la primera meta de los gobiernos. Su impacto perdura. Queda ahí. Abre espacios físicos para un desarrollo mutuo y amplía la innovación.

Estimo posible constituir un fondo latinoamericano para financiar un programa de infraestructura para nuestra región. Si cada país aporta el equivalente a un $0.5 \%$ de su producto o destina una parte de sus presupuestos de infraestructura, telecomunicaciones e informática a un fondo para realizar proyectos multinacionales, contaríamos con más financiamiento internacional, más alcance y más rendimiento.

Vincularse por Internet es dotar a nuestros pueblos de un sistema de redes de mejor cobertura y calidad, y es más fácil y eficaz si se ejecuta a nivel latinoamericano. 
Integración

latinoamericana

en el siglo XXI
La interconexión energética, a su vez, es decisiva para reducir costos y riesgos. Vemos en Brasil, República Dominicana y hace poco en Chile, fallas de los sistemas eléctricos. La nueva economía requiere de más KWH por unidad de PGB.

Nuestros gobiernos están y estarán siempre absorbidos por tareas apremiantes: la consolidación democrática, la reducción de la pobreza y de la desigualdad, la atracción de capitales externos para crecer. Si no se percibe un vínculo entre la solución de estas premuras con la integración, no habrá interés político relevante.

Los tres pilares aquí mencionados tienen atractivo, generan beneficios palpables. Dan pie para propuestas compartidas por la ciudadanía y enarbolables por los dirigentes políticos y sociales. 